Edited by Allan Beveridge, Femi Oyebode and Rosalind Ramsay

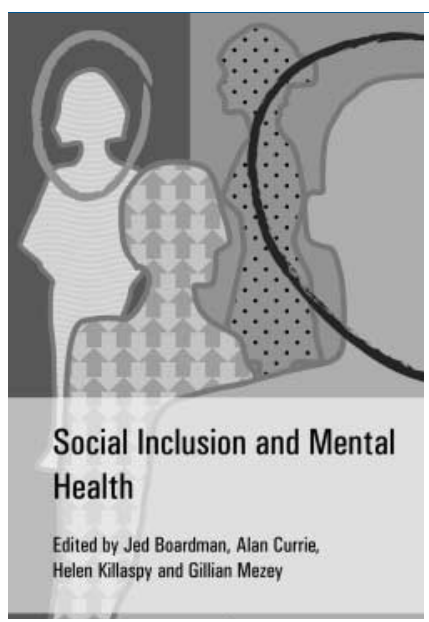

\section{Social Inclusion and Mental Health}

Edited by Jed Boardman, Alan Currie, Helen Killaspy \& Gillian Mezey. RCPsych Publications. 2010. £30.00 (pb). 410pp. ISBN 9781904671879

Nearly 30 years ago I wrote my first book review. I did not like the book and made this plain. What I did not know was that the book's author was on the Editorial Board of the journal for which I was reviewing. He was given a page-length opportunity to respond: the nature of our interaction was well summed up by the author's opening sentence. In response to my complaint of 'clotted jargon-ridden prose', the author thundered: 'Jargon is the language of science'. I learnt two valuable lessons from this early experience. One was not to agree to review a book about a topic that I did not have much understanding of. The other was the rather obvious fact that authors of academic books deserve respect, since they will have invested hard hours that will likely earn little or no reward.

I had always seen the concept of social inclusion/exclusion as the rather better-grounded sibling of the recovery movement. The fact that people who are involved with mental health services experience multiple social disadvantages is intuitively obvious and very well documented. It is also obvious that mental health services should be working to help people overcome the effects of experiencing mental illness on their life chances. This aspiration could easily be reworded as facilitating a move from a state of social exclusion to one of social inclusion. Social Inclusion and Mental Health, in the words of its publicity material, is 'concerned with ... the steps that psychiatrists and mental health workers can take to facilitate the social inclusion of people with mental health problems'.

There is no doubt that enormous effort and considerable erudition has gone into Social Inclusion and Mental Health, which is the product of a Royal College of Psychiatrists' working party, and like pre-Roman Gaul is divided into three parts.

The book is very copiously referenced in the academic and 'grey' literature surrounding a topic that turns out to be complex and contested. Part 1 - 'What is social exclusion?' - exhaustively delineates these difficulties. It includes a chapter on policy and social exclusion that is a rather poignant reminder of the wellmeaning policy preoccupations of the previous UK government and the times before our current era of austerity. Part 2, 'Social exclusion: the scope of the problem', provides empirical data and more discursive accounts of social exclusion in the general population and among people in contact with psychiatric services.
Service user and carer perspectives are included here. Part 3, 'Working towards inclusive psychiatry', seeks to offer solutions to the very obvious disadvantages that people with mental health problems experience. The more glamorous recovery paradigm often takes over the narrative here, and there were perhaps less practical ideas about what the practitioner and local services could do to foster social inclusion than one would expect.

Although its motivations are exemplary and the scholarship is sound, this book is not perfect. Occasionally opinion goes beyond any possible evidence base. Not all concepts are clearly elucidated (at least for this reader). The final chapter sets out a clarion call for socially inclusive practice and psychiatry in the 21 st century. The editors, in writing this chapter, were clearly aware that times were changing. It will be interesting to see how relevant their proposed solutions will be to the 2010s.

Frank Holloway Consultant Psychiatrist and Clinical Director, Croydon Integrated Adult Mental Health Service, South London and Maudsley NHS Foundation Trust, Bethlem Royal Hospital, Monks Orchard Road, Beckenham, Kent BR3 3BX, UK. Email: f.holloway@iop.kcl.ac.uk

doi: 10.1192/bjp.bp. 110.084350

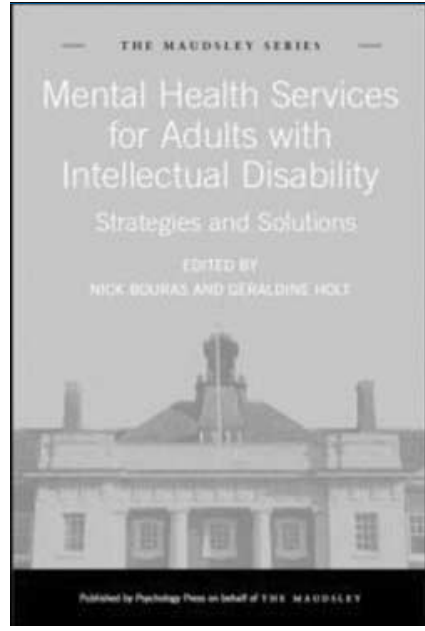

\section{Mental Health Services for Adults with Intellectual Disability: Strategies and Solutions}

Edited by Nick Bouras \& Geraldine Holt. Psychology Press. 2010 f22.46 (hb). 168pp. ISBN: 9781848720404

The specialism in the psychiatry of learning disability is only available in the UK and most of the recent advances in the clinical care of individuals with intellectual disabilities have occurred in the UK. That is not to say that developments of great consequence have not happened elsewhere, but it is my view that we have, perhaps, one of the better alignments of health and social care, with significant research output in this domain. Leading lights in promoting the mental health needs of people with intellectual disabilities have been Nick Bouras and Geraldine Holt.

This volume is meant to summarise years of academic and clinical endeavour and collect the advances that have been achieved in practice, underpinned by the research and audit completed under Professor Bouras' leadership.

I found the book informative and interesting. The first part was a history lesson in how our mental health service philosophy and provision has developed since de-institutionalisation to the present day. The style is flowing and discursive, which helps to attract the reader to what could otherwise be a stale litany of data.

I have only minor reservations stemming from the fact that one or two chapters do not help the central argument of the book, which is to discuss services and strategies for solving service problems and setting new directions (e.g. chapter 4 and 7). 
I would have liked to read more about the behavioural genetic clinic as it is one of a kind and I am aware that data based on its operation have been reported already. Finally, I was rather puzzled by the structure of chapter 8 which has lost some of its impact by discussing the training requirements for intellectual disabilities in various professions in the UK. I appreciate that this may have been included for the international readership but somehow it appeared to dilute the message of how important training is, in its wider sense, for further service maintenance and staff morale.
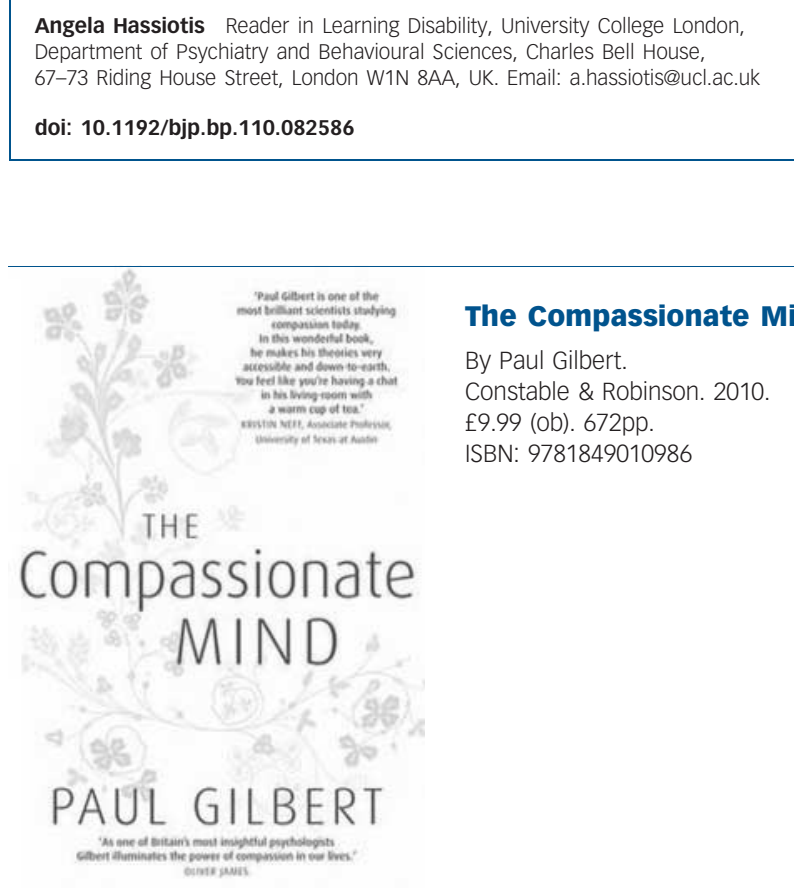

For many years Professor Paul Gilbert has been one of the most original and creative British clinical psychologists. This book not only confirms this status, but will bring him many more admirers. In part 1, Gilbert outlines the science behind compassion; in part 2, he talks about building the compassionate self through a number of skills and exercises. The breadth of sources used throughout the book reveals Gilbert's scholarship and ranges from Freud, Jung and Bowlby to Kelly, Beck and Ellis, to name but a few. He even manages to bring in the well-known but somehow never dated, experimental work of Asch, Zimbardo and Milgram.

What is compassion? Gilbert does not attempt a definition until page 217. Here he states, 'Compassion can be defined as behaviour that aims to nurture, look after, teach, guide, mentor, soothe, protect, offer feelings of acceptance and belonging in order to benefit another person.' However, quite a few of the exercises in part 2 are focused on the development of compassion towards the self. Compassionate mind training is about 'learning to bring balance to our three different types of emotion regulation systems - namely the system that focuses on threats to self-protection, the incentive resource seeking system that focuses on wants and achievements and the soothing contentment system that focuses on safeness and connectedness' (p. 477).

Gilbert's work ties in nicely with the current emphasis on wellbeing as seen in the government's New Horizons policy document. It is one of several approaches that provide an underlying theoretical structure for the concept of well-being. Given the length of the book and its 48 pages of notes, I am not sure of its utility as a stand-alone self-help guide. However, there is no doubt that it could form the basis of a very useful training course in developing compassion, both for mental health professionals and for people who use our services. It also has wider social implications for the sort of society we want to live in. Recommended.

Jerome Carson Consultant Clinical Psychologist, South-West Sector Community Mental Health Team, 380 Streatham High Road, London SW16 6HP, UK. Email: jerome.carson@slam.nhs.uk

doi: 10.1192/bjp.bp.109.068296

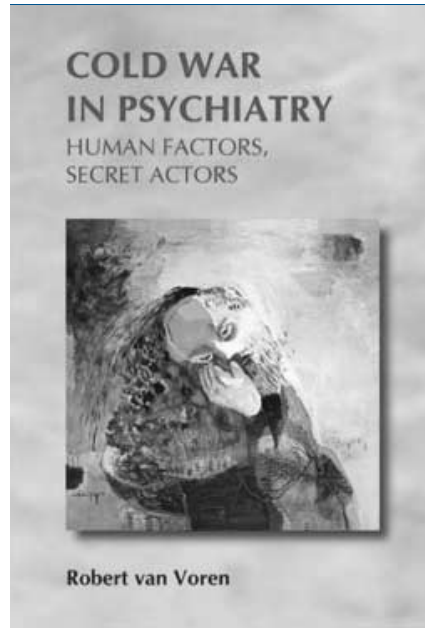

\section{Cold War in Psychiatry Human Factors, Secret Actors}

By Robert van Voren.

Rodopi. 2010

US\$54 (pb). $512 \mathrm{pp}$
ISBN: 9789042030480

Much has been written about the abuse of psychiatry in the former USSR. The advantage of this new book by Robert van Voren is that it shows the author at the forefront of the fight to expose the political abuses of that era. The introduction states that this is not a 'typical scholarly work' - it is to a large extent autobiographical. Nevertheless, the author's first-hand experience and his access to a wide range of references, from professional journals to personal interviews, make this book a valuable source of knowledge in this area.

As the title suggests, the focus is mainly on how the Cold War affected the practice of psychiatry, and the people who played key roles in the saga. The protagonists, apart from the author, are the former medical director of the American Psychiatric Association (APA), Melvin Sabshin, his colleague there, Ellen Mercer, and East German psychiatrist and former member of the World Psychiatric Association executive committee, Jochen Neuman.

The period covered is the volatile years of the 1980s and the struggle to bring the All-Union Society of Neuropathologists and Psychiatrists of the former USSR to account. Owing to the autobiographical nature of the book, the actors play a bigger part than the concepts. In fact, the first 92 pages tell the life stories of Melvin Sabshin and Jochen Neuman. The reader might find this part somewhat tedious but their stories are told not without joy and irony, and interest is maintained by the various interspersed historical facts.

There are also chilling truths about how psychiatry was used as an instrument of oppression. For instance, in the USSR the Hippocratic oath was replaced by the Oath of the Soviet Doctors, where the doctors' responsibility was ultimately to the Communist Party and not to their patients. Psychiatric institutions were caught up in the hierarchy of the state, leading to the lack of 